\title{
Selected Properties of Dental Composites
}

\author{
ROBERT G. CRAIG \\ School of Dentistry, The University of Michigan, Ann Arbor, Michigan 48109
}

\section{J Dent Res 58(5):1544-1550, May 1979}

The traditional parameters used to evaluate dental composites in the laboratory have been working time, polymerization contraction, compressive, tensile, shear, and bond strength, resistance to indentation, water sorption and solubility, leakage, color stability by the 24-hour ultraviolet lamp test, and thermal coefficient of expansion. Other less well documented properties of composites are their modulus of elasticity, abrasive wear, wetting by water or saliva, and staining.

It is the purpose of this paper to review the present state of knowledge of this latter set of properties and to attempt to interpret them with respect to the application of dental composite filling materials.

\section{Modulus of elasticity.}

The modulus of elasticity and Poisson's ratio in relationship to the corresponding values for tooth structure and cement bases are important in the compounding of composites and in the selection of cement bases to be used with composites. Typical values for the materials mentioned are listed in Table $1 .^{1-3}$

An axisymmetric three-dimensional finite element model (Fig. 1) was used to determine the maximum stresses in the composite restoration just above the line CD (Fig. 2) and the maximum stresses in the various cement bases supporting the composite 4 (Fig. 3).

The maximum stresses as shown in Fig. 2 were at the center of the composite. Modest compressive stress occurred at the center when the composite was supported by $2 \mathrm{~mm}$ of zinc phosphate or $1.5 \mathrm{~mm}$ of zinc phosphate over $0.5 \mathrm{~mm}$ of zinc oxideeugenol. High tensile stress resulted from the use of $0.5 \mathrm{~mm}$ of calcium hydroxide. Also, reduction of the maximum tensile stress resulted when $2 \mathrm{~mm}$ of zinc phosphate were used and further increased occurred when

Examination of the maximum stresses in the elements shown in Fig. 3 show that minimum stresses occurred when zinc polyacrylate was used. Increased tensile stress resulted when $2 \mathrm{~mm}$ of zinc phosphate was used and further increases occurred when $1.5 \mathrm{~mm}$ of zine phosphate was used over $0.5 \mathrm{~mm}$ of zinc oxide-eugenol. Modest compressive stresses were observed when 0.5 $\mathrm{mm}$ of calcium hydroxide was used.

It can be concluded that an optimum condition would result when the modulus of elasticity of the composite and cement base are equal. Also, it is readily possible to select a single or layered base and liner

TABLE 1

MODULUS OF ELASTICITY AND POISSON'S RATIO OF TOOTH STRUCTURE, COMPOSITES AND CEMENT BASES AND LINERS

\begin{tabular}{lcc} 
Material & $\begin{array}{c}\text { Modulus of Elasticity } \\
\text { MPa }\end{array}$ & $\begin{array}{c}\text { Poisson's } \\
\text { Ratio }\end{array}$ \\
\hline Human Enamel & 82,500 & 0.33 \\
Human Dentin & 18,500 & 0.31 \\
Dental Composites & 8,000 to 16,500 & 0.28 \\
Zinc Polyacrylate Cement Base & 5,000 & 0.25 \\
Zinc Phosphate Cement Base & 22,500 & 0.35 \\
Zoe Cement Liner & 290 & 0.40 \\
Calcium Hydroxide Liner & 370 & 0.40 \\
\hline
\end{tabular}




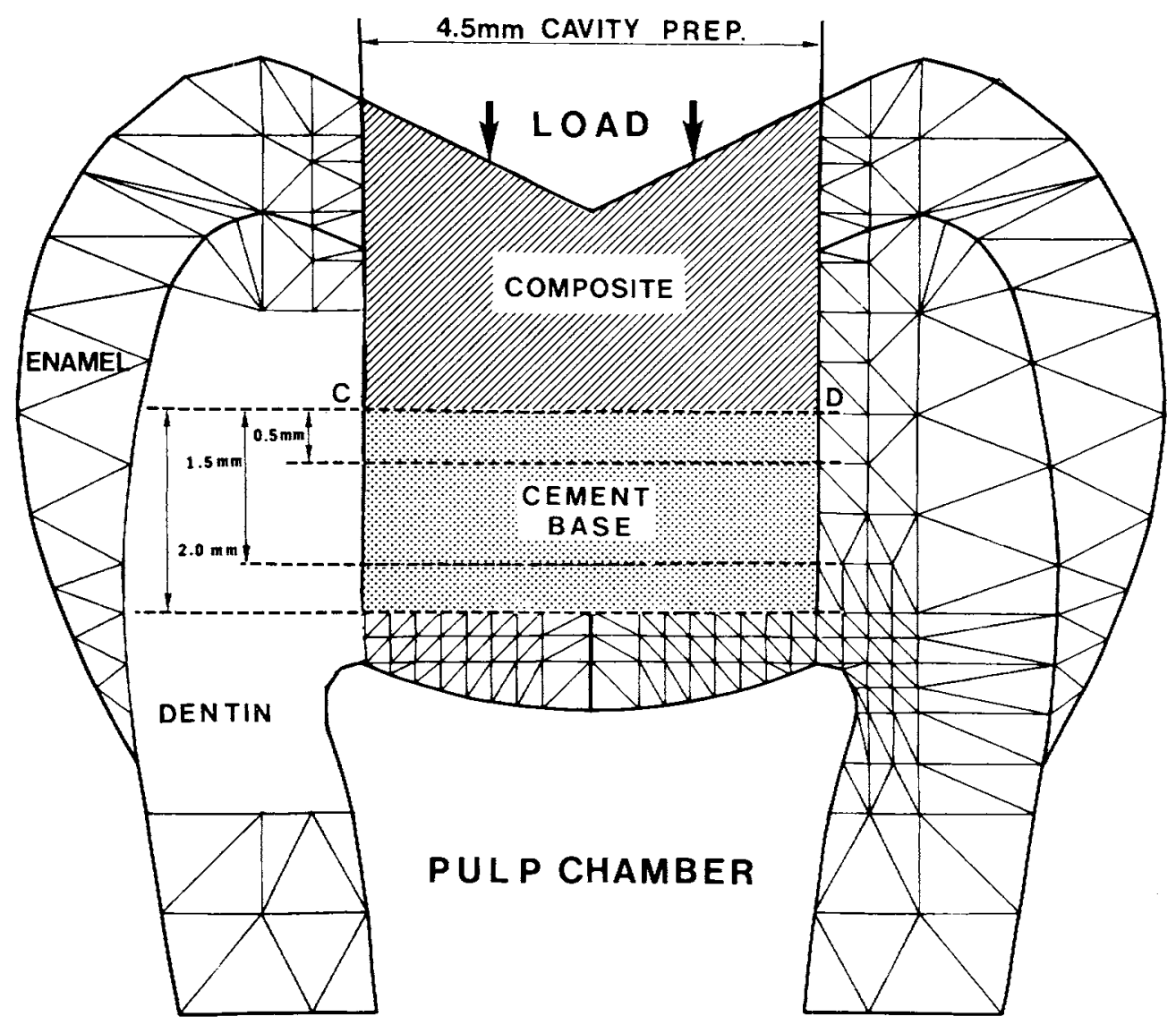

Fig. 1.-Axisymmetric finite element model of a tooth containing a composite supported by bases and liners. (From Farah, J. W., et al., J. Dent. Res., 55:116, 1976.)

under a composite that will fail as a result of biting forces and jeopardizing the success of the composite.

\section{Wear.}

The objective of a wear test may be to compare and rank a series of composites or it may be to examine the mechanism of the wear process. Tests for the former have consisted of two-body abrasion tests with some means to measure the volume loss of composite under a particular set of test conditions. Tests to examine the wear process include a single-pass sliding of an indenter and examination of the wear track.

\section{Two-body tests.}

Tests involving the sliding of cylinders of enamel on a disk of composite 5 and cylinders of composite on standard abrasive papers have been reported. $6-8$

The latter test has confirmed the importance of the silane treatment of the quartz or glass fillers since omitting the silane treatment approximately doubled the rate of wear when composites were abraded under water on 600 grit silicon carbide paper. ${ }^{6}$ The test also ranks the wear of composites as a function of the hardness and the amount of filler. At the same level of filler, composites containing glass wear approximately twice as fast as those containing quartz. 
The two-body abrasion test using silicon carbide, however, should not be used to compare composites with metals and alloys. It was conjectured that the high hardness of silicon carbide might be responsible for this problem and the effect of the hardness of the abrasive on the wear of composites was determined. 9 The wear rate of three com- posites was measured using glass, quartz, garnet alumina and silicon carbide abrasives. The wear rates are plotted as a function of the Knoop hardness of the abrasive in Fig. 4. With the exception of silicon carbide, the wear rate was linear with respect to the hardness of the abrasive. Also, the slope of these lines is a more sensitive parameter for

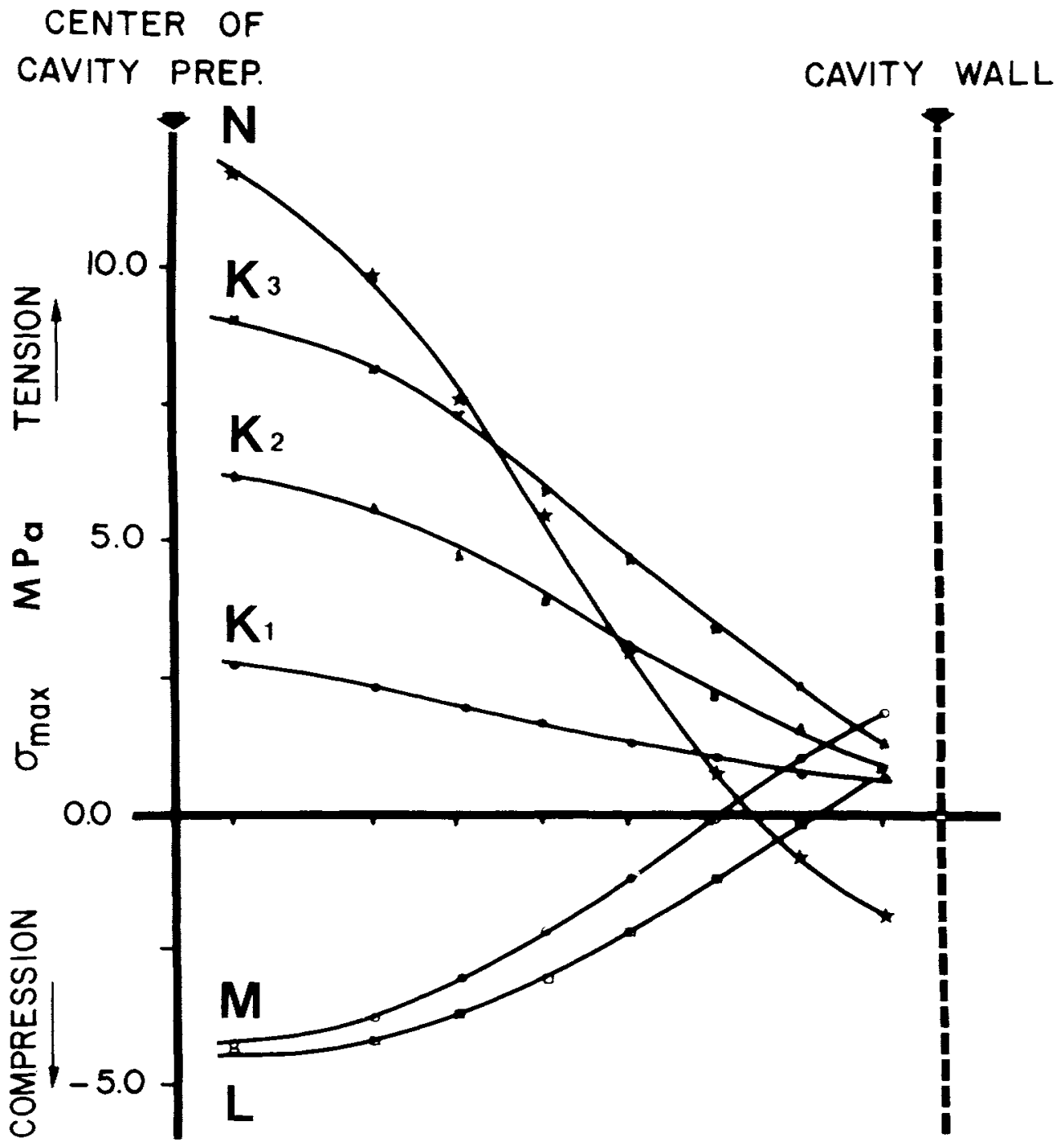

Fig. 2.-Maximum stresses in the composite above the line $\mathrm{CD}$ in the model in Figure 1. $\mathrm{N}$ is for composite of $8,000 \mathrm{MPa}$ modulus supported by $0.5 \mathrm{~mm}$ caicium hydroxide; $\mathrm{K}_{3}, \mathrm{~K}_{2}$, and $\mathrm{K}_{1}$ represent composites of $16,500,21,500$, and $8,000 \mathrm{MPa}$ moduli supported by $2 \mathrm{~mm}$ zinc polyacrylate cement base; $\mathrm{M}$ and $\mathrm{L}$ are for composite of $8,000 \mathrm{MPa}$ modulus supported by $1.5 \mathrm{~mm}$ zinc phosphate over $0.5 \mathrm{~mm}$ zinc oxide-eugenol and $2 \mathrm{~mm}$ zinc phosphate cement. (Adapted from Farah, J. W., et al., J. Dent. Res., 55: $117,1976)$. 


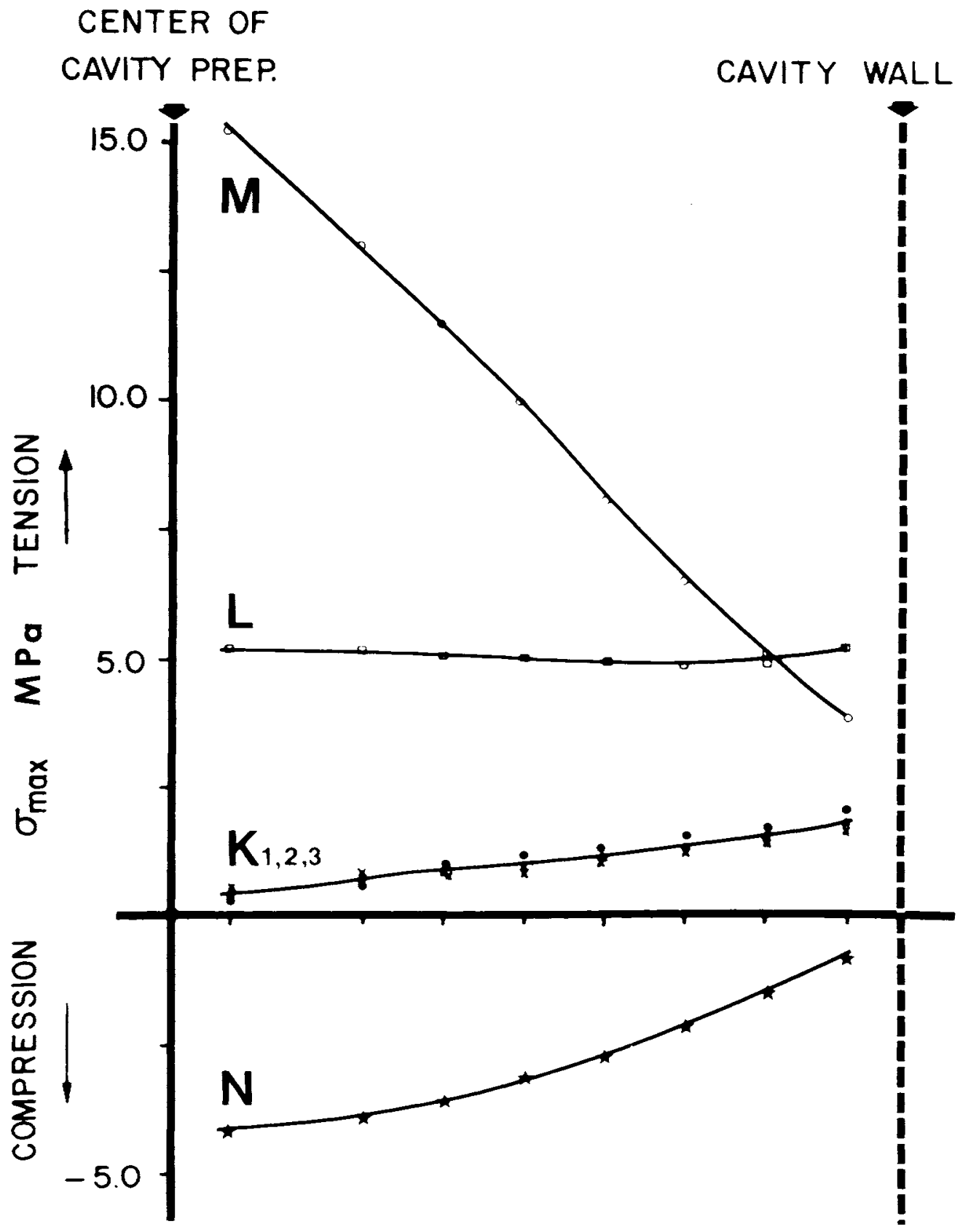

Fig. 3.-Maximum stresses in the various cements in the model shown in Figure 1. $\mathrm{M}$ is for composite of $8,000 \mathrm{MPa}$ modulus and $1.5 \mathrm{~mm}$ zinc phosphate over $0.5 \mathrm{~mm}$ zinc oxide-ugenol; $\mathrm{L}$ is for composite of $8,000 \mathrm{MPa}$ modulus and $2 \mathrm{~mm}$ zinc phosphate; $\mathrm{K}_{1,2,3}$ represent composites of moduli from 8,300 to $16,500 \mathrm{MPa}$ supported by $2 \mathrm{~mm}$ of zinc polyacrylate; $\mathrm{N}$ is for composite of $8,000 \mathrm{MPa}$ modulus supported by $0.5 \mathrm{~mm}$ calcium hydroxide. (Adapated from Farah, J.W., et al., J. Dent. Res., $55: 117,1976$.) 


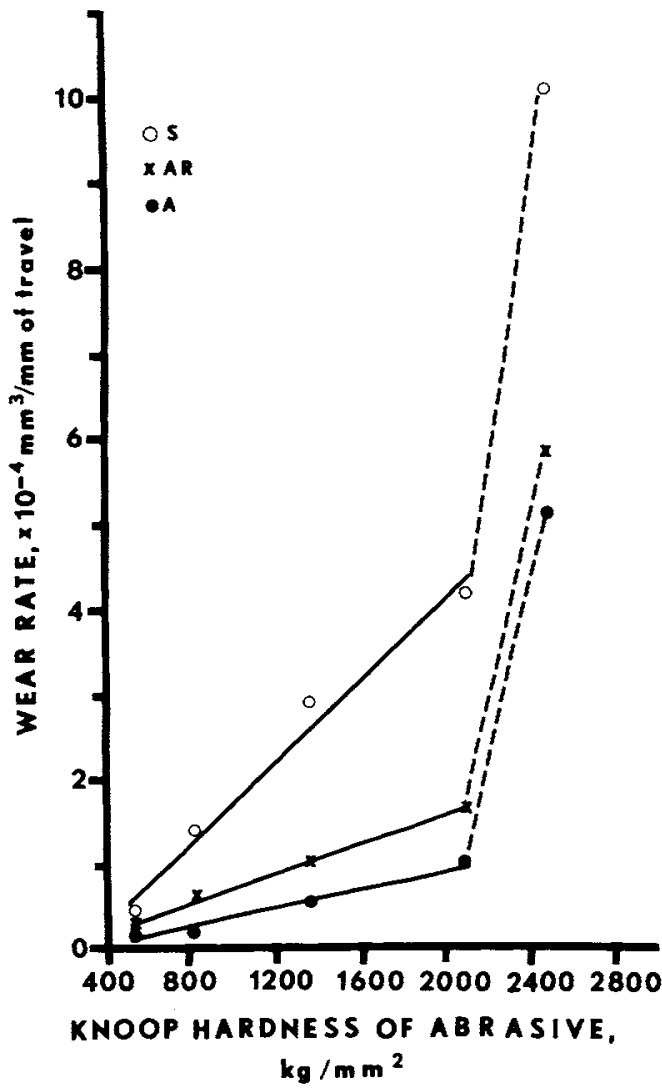

Fig. 4.-Wear rate of composites as a function of the Knoop hardness of the abrasive; o - Simulate, x - Adaptic Radiopaque, o - Adaptic. (From Rootare, H. M., Powers, J. M., and Craig, R. G. Wear of composites by abrasives of varying hardness. J. Dent. Res., submitted.)

evaluating wear than the rate for a given abrasive. It appears that in the future wear should be studied as a function of the hardness of the abrasive.

\section{Single track tests.}

Single track wear measurements have shown that sliding a diamond hemisphere over a composite and a determination of the tangential force or the track width permits a ranking of the wear resistance of composites in much the same way as does the two-body abrasion test. Increasing the normal load on the diamond indenter from minimal to high loads causes at some load a change from a ductile to a brittle mode of surface failure.
The appearance of the wear track can give an indication of the type of surface failure as seen in Fig. 5. It is apparent that the failure of the unsilanated composite is markedly different from the silanated composite. Also, the failure of the unfilled BIS-GMA sample showed marked tensile failure normal to the direction of sliding.

Attempts to correlate hardness and tensile strength to abrasive wear ${ }^{10}$ have shown that these parameters are not related in any simple way and should not be used to estimate wear of composites.

More recently, studies of the fracture toughness ${ }^{11}$ of composites and unfilled restorative plastics have confirmed the results of wear tests by the single-pass sliding method. Thus, it appears a combination of two-body abrasion and single-pass wear testing should improve our comparisons of wear rates and mechanisms.

\section{Wetting.}

The contact angle of water on human enamel is $45^{\circ}$ to $60^{\circ 12}$, on human dentin is $60^{\circ}$ to $80^{\circ} 12$, and on traditional BISGMA composites is $60^{\circ}$ to $65^{\circ 13}$. These values indicate moderate wetting of these materials. In the absence of chemical bonding of the composite to tooth structure any space between the cavity wall and the restorative material is spontaneously filled when brought into contact with water or saliva. This effect has been demonstrated by preparing an MO or DO preparation followed by placement of a glass capillary tube parallel to the axial wall, a shim of 0.001 inch polytetrafluoroethylene covering the base of the preparation, and then placing a composite restoration. After setting, the shim was removed producing a 0.001 inch space or leak. When this leak was placed in contact with water the liquid instantaneously penetrated the space indicated by water rising in the capillary tube.

Hydrophobic polymers have been prepared 13,14 and compounded to produce hydrophobic composites. The first polymer developed was a copolymer of heptafluorobutyl methacrylate and p-vinyl phenol which when compounded into a composite had a contact angle with water of $92^{\circ}$. A second polymer developed more recently is a copolymer of octafluoropentylmethacrylate and Diacryl 101 which when compounded into a 

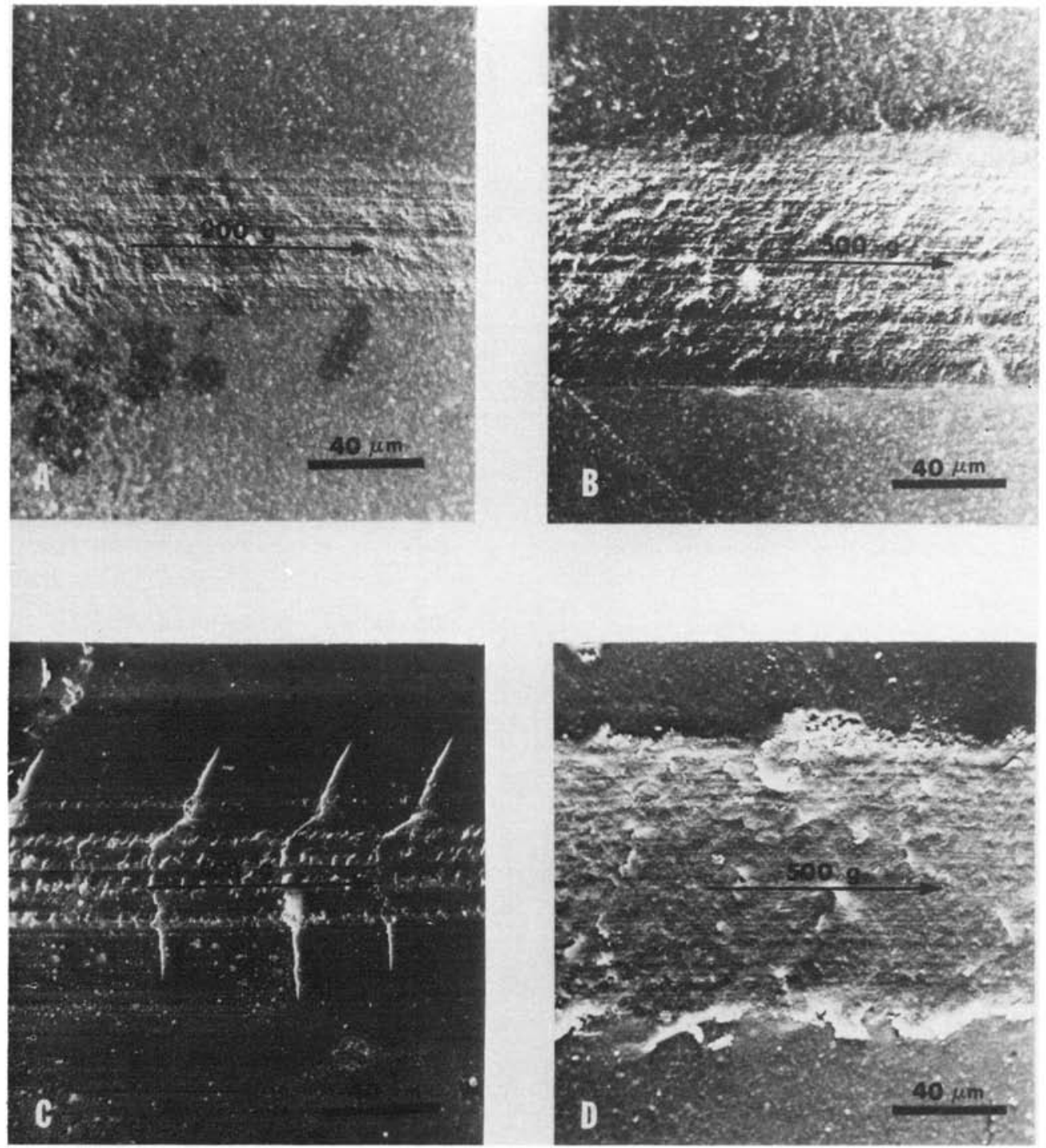

Fig. 5.-Scanning electron photomicrographs of wear tracks from a hemispherical diamond slider on Smile in water with a $200 \mathrm{~g}$ normal load (A), a $500 \mathrm{~g}$ normal load (B), on unfilled Smile under a $500 \mathrm{~g}$ normal load (C), and on unsilanated Smile under a $500 \mathrm{~g}$ normal load (D). (From Craig, R. G., and Powers. J. M. Internat. Dent. J., 26:130,1976.)

composite possessed a contact angle with water of $156^{\circ}$ when finished with 600 grit abrasive. When this composite was evaluated by the capillary-leak test previously described, water would not spontaneously penetrate the 0.001 inch leak. Penetration was accomplished when a pressure equivalent to 2 $\mathrm{cm}$ of water was applied. It should be noted that a 0.001 inch leak is a large space and smaller spaces would require higher pressures to cause penetration of water if the composite is hydrophobic. On the other hand, when the composite is hydrophilic, as are commercial composites, penetration is enhanced by smaller spaces. Therefore, the development of hydrophobic composites 
provides the opportunity to reduce or eliminate marginal leakage even in the absence of chemical bonding.

Another aspect of hydrophobic composites is their ability to inhibit staining. The hydrophobic composite containing octafluoropentyl methacrylate and Diacryl 101 and a commercial BIS-GMA composite were subjected to two staining regimes. ${ }^{15}$ The first test involved soaking the composite in a $1 \%$ methylene blue solution in water for one week, followed by rinsing with water and comparison with an unexposed sample. No perceptible staining occurred on the hydrophobic composite and very pronounced staining was observed on the BISGMA composite.

A second staining test involved pretreatment of the composites with citrate and chlorhexidine, followed by staining with tea. The BIS-GMA composite again showed pronounced staining and the hydrophobic fluorinated composite only slight evidence of staining.

Another interesting quality of the hydrophobic fluorinated composite is the low water sorption of $0.09 \mathrm{mg} / \mathrm{cm}^{2}$ and the rapid equilibrium with water of less than 48 hours, indicating a high rate of diffusion.

At the present level of development the hydrophobic composites possess important differences in properties compared with commercial BIS-GMA composites. These differences at present are gained with a reduction in compressive strength of $15 \%$ and in tensile strength of $30 \%$. In spite of these decreases, the abrasive wear of the commercial and hydrophobic composites are not significantly different.

In summary, it appears that modifications in the polymer phase of composites, as well as inorganic phases and coupling agents, offer ample opportunities to continue the development and improvement of composite restorative materials.

\section{REFERENCES}

1. DENNISON, J. B.; and CRAIG, R. G.: Physical properties and finished surface texture of composite restorative resins. $J A D A, 85: 101$ $8,1972$.
2. HALL, D. R.; NAKAYOMA, W. T.; GRENOBLE, D. E.; and KATZ, J. L.: Elastic constants of three representative dental cements. J. Dent. Res., 52:390, 1973.

3. POWERS, J. M.; FARAH, J. W.; and CRAIG, R. G.: Modulus of elasticity and strength properties of dental cements. $J A D A, 92: 588$ 91, 1976.

4. FARAH, J. W.; POWERS, J. M.; DENNISON, J. B.; CRAIG, R. G.; and SPENCER, J.: Effects of cement bases on the stresses and deflections in composite restorations. J. Dent. Res., 55:115-20, 1976.

5. POWELL, J. M.; PHILLIPS, R. W.; and NORMAN, R. D.: In vitro wear response of composite resin, amalgam, and enamel. $J$. Dent. Res., 54:1183-95, 1975.

6. POWERS, J. M.; ALLEN, L. G.; and CRAIG, R. G.: Two-body abrasion of commercial and experimental restorative and coating resins and amalgam. $J A D A, 89: 1118-22,1974$.

7. CRAIG, R. G.; and POWERS, J. M.: Wear of dental tissues and materials. Internat. Dent. J., 26:121-33, 1976 .

8. POWERS, J. M.; ROBERTS, J. C.; and CRAIG, R. G.: Surface failure of commercial and experimental restortive resins. J. Dent. Res., 55:432-6, 1976.

9. ROOTARE, H.M.; POWERS, J. M.; and CRAIG, R. G.: Wear of composites by abrasives of varying hardness. Abstr. J. Dent. Res., Spec. Iss. A 57:252, 1978.

10. HARRISON, A.; and DRAUGHN, R. A.: Abrasive wear, tensile strength, and hardness of dental composite resins - is there a relationship? J. Prosth. Dent., 36:395-8, 1976.

11. ROBERTS, J. C.; POWERS, J. M.; and CRAIG, R. G.: Fracture toughness of composite and unfilled resins. J. Dent. Res., 56: 748-53, 1977.

12. UY, K. C.; and CHANG, R.: An approach to the study of the mechanism of adhesion to teeth, pp 103-28. (In Austin, R. N., Wilsdorf, H. G. F., Phillips, R. W., eds. Adhesive restorative dental materials -11 , Washington, D.C., U.S. Dept. Health, Education, and Welfare, $1965 . \mathrm{xi}+293 \mathrm{pp}$ )

13. CRAIG, R. G.; and WANG, T. K.: An experimental hydrophobic composite restorative system. Abstr. J. Dent. Res., Spec. Iss. B, $56: \mathrm{B} 216,1977$.

14. DOUGLAS, W. H.; CRAIG, R. G.; and CHEN, C. -J.: Visible light initiated hydrophobic composite from fluoromethacrylate. J. Dent. Res., Spec. Iss. A., 57:250, 1978.

15. DOUGLAS, W. H.; and CRAIG, R. G.: Unpublished data, 1978. 